\title{
Filosofia e pensamento social russo: continuidades depois da Revolução de Outubro
} GALIN TIHANOV ${ }^{I}$

A HISTÓRIA intelectual apresenta uma série de continuidades e descontinuidades, às vezes simultâneas, que se desenvolvem ao longo do tempo dentro das culturas. Neste ensaio, vou me concentrar nas continuidades frequentemente ocultas por mudanças políticas dramáticas - que permeiam a cena da filosofia e do pensamento social russo no período soviético, desde a Revolução de Outubro, em 1917, até a dissolução da URSS em 1991. A limitação do espaço fez que decisões difíceis tivessem de ser tomadas em relação ao que deveria ser incluído e ao que seria deixado de fora. Uma vez que o paradigma intelectual dominante do período era o marxismo, não há dúvidas de que qualquer tratamento sério da questão da continuidade deve não apenas se dirigir ao marxismo, mas colocá-lo no centro da atenção. Ignorar o marxismo e preferir explorar apenas os diversos discursos não marxistas teria resultado no fracasso em apreender o lugar crucial deste na dinâmica frequentemente subterrânea entre estabilidade e mudança, que sustentava e atravessava os discursos públicos da filosofia e das ciências sociais no período soviético. Com referência ao marxismo, a continuidade inscrita nessa dialética de permanência e transformação teve dois aspectos importantes: a consciência e posicionamento do marxismo soviético frente à filosofia ocidental não marxista e, através disso, mas também independentemente disso, frente ao pensamento russo pré-1917.

A segunda parte do ensaio examina vários discursos de excepcionalismo, concentrando-se no renascimento do eslavofilismo, do pótchvennitchestvo (uma corrente de pensamento que se formou nos anos 1860 e que tinha afinidades com o eslavofilismo, mas era mais abertamente conservadora e às vezes também antissemita) e do eurasianismo. Serão deliberadamente enfatizados os desenvolvimentos dentro da União Soviética. Optei por não incluir uma abordagem separada das correntes dos intelectuais da emigração, pois isso reproduziria uma noção equivocada de que eles foram os únicos herdeiros da tradição anterior a 1917, reforçando assim uma imagem sustentada por muito tempo, e um tanto enganosa, de um abismo constante e intransponível entre a vida intelectual soviética e a emigrada. A diáspora e o continente foram envolvidos em uma dinâmica de impacto historicamente oscilante, com a cultura e o pensamento soviético sendo mais influente entre a diáspora antes da Segunda Guerra Mundial, 
seguida, especialmente depois dos anos 1960, por um longo período em que o pensamento emigrado (de origem tanto anterior quanto posterior à Segunda Guerra Mundial) era cada vez mais relevante para os debates soviéticos. A identificação detalhada do impacto dos desenvolvimentos intelectuais soviéticos nas muitas correntes de pensamento da emigração, assim como o exame minucioso da relevância deste para a vida intelectual soviética são tarefas para o futuro (para citar apenas um exemplo importante, ainda não há um estudo detalhado sobre a recepção do marxismo soviético na diáspora russa antes de 1945). Aqui poderei apenas começar a apontar a pauta geral, esboçando muito brevemente as (des) continuidades reveladas no renascimento do eurasianismo na União Soviética. (Outros casos instrutivos, bastante pesquisados até o momento, incluem as sobreposições e trocas entre os pensadores emigrados e os intelectuais que viviam na União Soviética, envolvidos na apropriação - em Harbin, Praga, Paris, Moscou, Kaluga e Minsk (para citar apenas algumas localidades) - das ideias de Nikolai Fiódorov, assim como o impacto das obras de Berdiáev na emigração, em particular de A nova Idade Média, nos anos 1960, que junto com A nova classe, de Milovam Djila, se transformaram em inspiração para o grupo de oposição VSKhSON (União Cristã-Social Russa para a Libertação do Povo), estabelecida em Leningrado, em 1964).

Finalmente, para os propósitos deste artigo, optei por enfocar as continuidades com o pensamento russo pré-1917. Essa opção não é trivial. As sete décadas de história soviética foram suficientemente longas para que continuidades começassem a se desenvolver entre os pontos focais do pensamento elaborados depois da Revolução de Outubro. Mas esse processo foi dificultado por muitos fatores e começou a ganhar proeminência apenas no final do período soviético. Assim, ao longo dos estágios formativos da Escola de Tártu-Moscou de semiótica e história cultural, nem Chpet (que nos anos 1920 publicou importantes obras que prenunciaram muitos princípios do estruturalismo e da semiótica), nem Lóssev (um dos primeiros filósofos da União Soviética a considerar os conceitos de "signo" e "estrutura") foram ativamente apropriados por Lótman e seus colegas. Lóssev chegou a reclamar em 1968 de não ser citado nessas obras (cf. Egórov, 1999, p.140). Apenas Floriénski fora recebido e apropriado de forma mais intensa pela Escola de Tártu-Moscou. Essa linha de continuidade amplamente quebrada nos anos 1960 contrasta com o impacto das obras de Bakhtin em meados dos anos 1980. Bakhtin não apenas deixou um traço visível em uma série de estudos especializados de história e literatura nos anos 1970 e 1980 por proeminentes intelectuais como Likhatchióv, Aviérintsev e Guriévitch, como em 1991, no ano do colapso da União Soviética, sua teoria do dialogismo havia se tornado a pedra angular da doutrina de "diálogo entre culturas" de Valdimir Bíbler, que fez que ele e seus colaboradores desenvolvessem um novo currículo escolar e uma nova filosofia da educação. Assim, ainda que no epílogo eu acrescente outro exemplo significativo da filosofia da história e da cultura soviética que se relacionou com o pensamento soviético inicial, esta exposição se 
atém principalmente às continuidades que formam uma ponte para os desenvolvimentos intelectuais pré-revolucionários.

\section{Continuidades dentro do marxismo soviético}

A ruptura política de 1917 e a subsequente consolidação do marxismo como ideologia dominante obscureceram por muito tempo muitos pontos de continuidade importantes com o passado. Em primeiro lugar, até 1930, quando A dialética do mito, de Lóssev, foi publicada em Moscou (em que o autor qualifica o materialismo dialético como um "absurdo gritante" [(Lóssev, 2001, p.63; também Scanlan, 1985, p.12]), a filosofia não marxista e a divulgação de seus resultados permaneceu algo legítimo. Em segundo lugar, a espinha dorsal da educação filosófica ainda incluía, até os anos 1940, manuais pré-revolucionários, assim como obras de um número significativo de filósofos não marxistas (muitos dos quais - embora não todos - atraídos para a órbita do materialismo e da dialética como seus predecessores). No final dos anos 1920, mesmo no principal Instituto de Professores Vermelhos os manuais sobre história da filosofia anteriores a 1917 ainda eram amplamente utilizados (cf. Kozlova, 1994, p.96-112); quando a lógica foi restabelecida no currículo, em 1946, o uso de um manual pré-revolucionário de Tchelpánov foi autorizado (cf. Wetter, 1960, p.525). De acordo com dados oferecidos por Mítin, um dos filósofos oficiais mais poderosos de Stalin, entre 1847 e 1916 foram publicadas mil cópias das obras de Aristóteles; 4.500, de Hegel; e 7.700, de Espinosa. Entre 1917 e 1938, esses números cresceram, respectivamente, para 78.300, 200.550 e 55.200 (cf. Mítin, 1943, p.22). Ainda em 1936, a leitura obrigatória para os exames orais de pós-graduação em filosofia no Instituto de História, Filosofia e Literatura incluía - ao lado de Marx, Lenin e Stalin - Kant, Hegel, Aristóteles, Bacon, Hobbes, Locke, Descartes, Espinosa, Leibniz e Hume (Charápov, 1995, p.26). A única fraqueza aparente do currículo de filosofia, afora a interpretação ideológica, rigidamente controlada, era a negligência da filosofia ocidental do século XX. Mesmo depois que a lista de autores ocidentais canônicos foi ampliada, seguindo as sugestões de uma reforma curricular em 1938, ela chegava apenas até Nietzsche (cujo ano de morte - 1900 - é indicativo da desconsideração da filosofia não marxista do século XX). ${ }^{1}$

Mas o mais importante é que, em meados dos anos 1920, o marxismo soviético ainda carregava as marcas de nascimento de uma tradição de pensamento derivada do cruzamento do "marxismo legal" russo, do "socialismo cristão" e de várias tentativas de reconciliar o marxismo com o neokantianismo e a filosofia de Mach. Três dos representantes mais ilustres do pensamento religioso russo no século XIX - Berdiáev, Serguei Bulgákov e Frank - na realidade iniciaram suas carreiras intelectuais como simpatizantes do marxismo e da ideia socialista. Outros, notadamente Lunatchárski e Górki, se engajaram com o marxismo como parte de uma plataforma social que apresentava uma poderosa mistura de idealismo religioso e ativismo nietzschiano radical (a doutrina resultante, 
cujos vestígios permaneceram influentes nos anos 1920, é geralmente nomeada como bogostroitelstvo [construção divina]). Outros ainda, em especial Plekhánov e Bogdánov, ancoraram o marxismo num paradigma de pensamento que era ou mais amplamente sociológico (Plekhánov), ou enraizado numa apropriação mais favorável da filosofia ocidental contemporânea (Bogdánov). Ainda que Bogdánov nunca tivesse sido admitido ao cânone oficial do marxismo soviético (ele foi criticado nos anos 1920 por pretender dissolver o marxismo em sua "ciência geral da organização", a chamada tectologia ${ }^{2}$ ), Plekhánov, cuja obra pertencia quase inteiramente ao período pré-1917, desfrutava de uma reputação menos homogênea. Ela refletia as ondas de relaxamento e ossificação da doutrina oficial e as sucessivas mobilizações do marxismo em razão do estabelecimento da autoridade de Stalin e da promoção da pauta de construção nacional. $\mathrm{Na}$ maior parte dos anos 1920, Plekhánov permaneceu uma autoridade para todos os que buscavam inscrever o marxismo em uma tradição materialista de pensamento que pudesse arrogar um pedigree sério, que remontava a Espinosa. (Deborin [1929, p.26] chegou a elaborar uma distinção entre Lenin e Plekhánov, descrevendo o último - numa chave positiva - como "o teórico", enquanto Lenin era elogiado por ser "o homem de ação, o político, o líder"). No início dos anos 1930, contudo, Plekhánov caiu em desgraça exatamente pelo mesmo motivo: foi criticado por considerar o materialismo dialético apenas como uma vertente, e não essencialmente diferente de outras variantes do materialismo no pensamento ocidental. Na mesma época, ele se tornou inaceitável por sua advertência de que a Rússia soviética não tinha passado por uma evolução capitalista suficientemente longa, e que, portanto, o socialismo não pôde emergir como resultado de um processo natural de radicalização das contradições do capitalismo. Ainda no início dos anos 1940, em meio a uma onda de propaganda nacionalista durante a guerra, Plekhánov ressurgiu novamente como parte do cânone do pensamento marxista russo. Pável Iúdin, em 1943, o alçou à condição de "maior e mais notável marxista, depois de Marx e Engels, da época pré-Lênin", "um grande patriota" e pensador que enriqueceu "a cultura nacional russa" (Iudin, 1943, p.18, 20).

A tentativa consistente e, nos anos 1920, ainda influente de Plekhánov de derivar o marxismo, incluindo sua compreensão de sociedade e de mudança social, da tradição do materialismo ocidental é uma ilustração útil de continuidades típicas do período soviético. A evolução do marxismo soviético foi marcada por uma necessidade incessante de lidar com seus antecessores supostos e reais; o estabelecimento da genealogia intelectual do marxismo continuou depois de 1917 e foi um aspecto do pensamento marxista na União Soviética que não perdeu impulso mesmo nas décadas do stalinismo. Duas figuras da filosofia ocidental se tornaram os principais pontos de referência desse debate: Hegel e Espinosa, embora a busca por predecessores legítimos, em geral, se estendesse e incorporasse Feuerbach, assim como os maiores representantes do idealismo alemão do século XIX. ${ }^{3}$ Tanto Espinosa quanto Hegel eram preocupações gené- 
ricas para o marxismo (como comprovam as obras de marxistas ocidentais sobre Espinosa, notadamente de Althusser e Balibar, e sobre Hegel, de Lucio Coletti e Antonio Negri), mas os debates soviéticos eram particularmente intensos. No começo dos anos 1930, a literatura russa sobre Espinosa excedia em quantidade a de qualquer outro país no Ocidente. A publicação de De Espinosa a Marx (1925), de Lunatchárski, era parte integrante da crescente polêmica acerca de Espinosa que ocorreu na segunda metade dos anos 1920.

A persistente preocupação com Hegel era de particular importância para o marxismo soviético, pois o colocaria em contato inicialmente direto (depois cada vez mais mediado) com uma tradição bastante longa de apropriações filosóficas não marxistas russas do filósofo alemão, que vai desde os eslavófilos até Ivan Ilin, que apenas um ano depois da Revolução de Outubro publicou um estudo em dois volumes sobre Hegel e a "concretude de Deus e do homem". Diz-se que Lenin, cujos Cadernos filosóficos (publicados postumamente em 1929) continham amplas evidências de sua ambição de dominar a metodologia de Hegel, gostou tanto desse livro que decidiu libertar Ilin da prisão (o que não impediu que ele fosse deportado em 1922). ${ }^{4}$

\section{Discursos de excepcionalismo}

Se o marxismo soviético foi capaz de manter o diálogo com o pensamento não marxista, ou pelo menos demonstrar certo grau de consciência e reflexividade ante as tradições do pensamento russo pré-1917, outras correntes intelectuais eram muito mais proeminentes no papel de guardiões da tradição. Além de uma série de intelectuais do século XIX ativamente apropriados e frequentemente interpretados de uma forma um tanto rígida pelo marxismo soviético como precursores do pensamento revolucionário (Belínski, Herzen, Tchernichévski, Píssarev), um corpus alternativo mais amplo do pensamento russo foi gradualmente reorganizado na União Soviética. Inicialmente, isso incluiu apenas pensadores e escritores do século XIX: cinco "Cartas Filosóficas" inéditas de Tchaadáiev foram publicadas já em 1935, juntamente com a autobiografia de Leóntiev (nos volumes 22 a 25 da prestigiosa série Literatúrnoe nasliédstvo). Mais tarde, durante os anos do "degelo", as histórias da filosofia russa de Lósski e Zenkóvski apareceram na União Soviética em pequenas tiragens (em 1954 e em 1956, respectivamente); a disseminação foi restrita em ambos os casos para pessoas da hierarquia do partido e aqueles que ocupavam posições de liderança na vida ideológica soviética.

A redescoberta do pensamento religioso russo começou de fato no final dos anos 1960 e começo dos anos 1970, com uma série de artigos escritos para a Enciclopédia Filosófica soviética em cinco volumes, editada por Lóssev, Aviérintsev, Ásmus, Khorúji e outros. O artigo sobre Solovióv no ultimo volume (1970) era, para surpresa de muitos, mais longo do que o texto sobre Engels. ${ }^{5}$ Esse volume em particular também continha artigos sobre Khomiakóv, Floriénski, Chestóv, Fiódorov e outros pensadores religiosos, todos escritos com detalhes 
informativos e tom respeitoso. Uma edição em dois volumes da obra de Skorovodá apareceu em 1973, seguida de um volume dos escritos de Ivan Kiréievski em 1979, mas provavelmente o evento mais agitado dos anos 1980, ainda antes das reformas de 1985 de Gorbatchóv, foi o aparecimento de um volume de ensaios selecionados de Fiódorov, em 1982, editado pelo renomado estudioso de Kant e Schelling, Arsiéni Gulíga, e retirado das livrarias logo após a publicação (Fedorov, 1982). Juntamente com Lóssev, Gulíga começou a trabalhar nos anos 1970 em uma edição em três volumes das principais obras de Solovióv, que veio a se materializar em uma seleção em dois volumes publicada em 1988. Nesse mesmo ano, uma resolução do Politburo decretou que uma série de republicações de filosofia russa não marxista seria lançada em 1989. Berdiáev, Chpet, Bakúnin, Tchaadáiev, Floriénski, Frank, Rózanov, Lóssev, Kropótin, Ern, Iurkiévitch, assim como os importantes volumes coletivos Marcos e Das profundezas, foram todos publicados nessas séries entre 1989 e 1991.

É crucial, contudo, que essa cronologia de redescoberta não deve ocultar o fato de que, como observa V. A. Smirnóv em suas memórias de Valentin Ásmus, as edições de filosofia russa anteriores a 1917 na realidade sempre estiveram disponíveis em bibliotecas públicas; elas nunca foram parte de coleções especiais e, nos anos posteriores à Segunda Guerra Mundial, elas também podiam ser adquiridas em lojas de livros usados. Quando, no começo dos anos 1970, círculos religiosos clandestinos começaram a se formar em Leningrado, as obras de Berdiáev, Floriénski e Serguêi Bulgákov eram discutidas em reuniões (frequentadas às vezes por grupos de trinta a cinquenta pessoas) (Pazuchin, 1992, p.33-50. esp. p.38). Do modo semelhante, quando as reuniões da Sociedade Antroposófica foram retomadas em Moscou em 1969, as obras russas e ocidentais anteriores a 1917 voltaram a ser lidas e estudadas. O pensamento russo pré1917 foi, então, revivido e estudado em ondas de apropriação e acomodação que, sem dúvida, eram politicamente condicionadas e submetidas a considerável censura, mas que, contudo, estavam em evidência muito antes do momento mais propício nos anos 1980.

Ilustrarei esse argumento com um breve olhar sobre a apropriação, na União Soviética, de dois poderosos discursos de excepcionalismo anteriores a 1917, o eslavofilismo e o pótchvennitchestvo. Por cerca de duas décadas depois de 1917, o eslavofilismo parecia inteiramente esquecido; sua carga conservadora significava que ele era considerado absolutamente incompatível com os princípios da ideologia soviética. No começo dos anos 1920, quando o controle ideológico ainda era frouxo, Chpet $(1922$, p.37) fez a famosa afirmação de que foram os eslavófilos que formularam "os únicos problemas originais da filosofia russa”. Bakhtin, em suas aulas privadas sobre literatura russa, realizadas nos anos 1920, recomendou o eslavofilismo como "um fenômeno significativo na história do pensamento russo", e designando o ocidentalismo como "apenas uma bolha de sabão que não produziu nada além de algumas frases antes de estourar" (Bakhtin, 2000, v.II, p.427). Na Academia Estatal de Ciências Artísticas 
(GAKhN), da qual Chpet foi vice-presidente de 1924 a 1929, Lóssev apresentou, em março de 1928, um ensaio aparentemente intrigante sobre a estética e a teoria da linguagem de Konstantín Aksákov. ${ }^{6}$ Mesmo assim, foi apenas no final dos anos 1930, quando a política stalinista de russificação e de construção da nação aumentou de ritmo e o discurso de naródnost ressurgiu nas discussões públicas, que o eslavofilismo foi de fato colocado em pauta. A questão-chave era como avaliar o eslavofilismo historicamente, como discernir - a partir de uma perspectiva marxista - o que havia de progressista e de retrógrado na plataforma dos eslavófilos. Esse debate começou em 1939, com um artigo de Nikolai Drujínin (1939, p.125-45, 197-200, aqui p.125) sobre "Herzen e os eslavófilos", no qual ele faz a forte (mas imprecisa) afirmação de que nenhuma pesquisa havia sido publicada sobre os eslavófilos desde 1917. Dois anos mais tarde, Serguei Dmítriev (1941, p.85-97) contribuiu para o mesmo periódico com um artigo em que, ao mesmo tempo em que estigmatizava o eslavofilismo como "uma variedade do romantismo nacionalista e reacionário", tomou a liberdade de observar alguns traços progressistas e concluiu que, objetivamente, os eslavófilos eram a favor da "via prussiana" para o capitalismo russo. Essa relativização da oposição entre eslavófilos e ocidentalistas era um elemento novo, e foi criticado inequivocamente na discussão subsequente. ${ }^{7}$

A visão convencional dos eslavófilos como defensores da tradição e pensadores com inclinações conservadoras inconfundíveis não foi superada durante os anos 1940, mas foi defendida com argumentos que poderiam potencialmente desestabilizar a ideologia oficial. Lídia Ginzburg (1940), uma das intelectuais liberais mais notáveis do período soviético, em um livro publicado em $1940,{ }^{8}$ voltou sua atenção para Lérmontov, que conheceu Samárin e Khomiakóv e cuja poesia era apreciada nos círculos eslavófilos. Na verdade, Ginzburg (1940) produziu argumentos que enfraqueciam a hipótese da afinidade entre Lérmontov e os eslavófilos. Mas, ao fazer isso, ela chegou a uma versão subversiva do cânone literário soviético. De acordo com Ginzburg (1940, p.219-20), nos anos 1840 houve entre os ocidentalistas de esquerda uma corrente que preferia Lérmontov, contra uma distinta preferência dos eslavófilos por Púchkin. Assim, na descrição de Ginzburg, a supremacia e o espaço reservado a Púchkin no cânone foram submetidos a escrutínio e questionados, tornando-se manchados pela associação com o campo conservador eslavófilo.

O livro de Ginzburg é importante ainda em outro sentido. Ele indica o fato de que os debates sobre o eslavofilismo na União Soviética começariam, assim como foi o caso antes de 1917, como debates sobre literatura e estética, mas terminariam como discussões ideológicas e filosóficas. Isso não se deve apenas ao fato de os eslavófilos serem eles mesmos literatos (ainda que não muito bem-sucedidos), mas também porque questões de identidade, cultura e linguagem eram tão centrais para os seus empreendimentos como para os dos filósofos, historiadores e críticos literários soviéticos que examinaram suas obras. A literatura e a estética se tornaram o ponto focal do segundo momento decisivo dos deba- 
tes soviéticos sobre o eslavofilismo, e uma plataforma para tentativas de reavaliar o significado cultural e político geral do eslavofilismo. Essa segunda discussão ocorreu no final dos anos 1960, começando com Questões de literatura e continuando na mesma revista e em Novo mundo, em 1969, ano que viu a publicação de um representativo volume dos poemas e peças de Khomiakóv (1969) em Leningrado. Entre os participantes havia dois estudiosos da literatura, Boris Egórov e Vadim Kójinov, representando duas orientações bastante distintas da paisagem intelectual soviética. Enquanto Egórov era próximo de Lótman e da escola de Tártu (depois da morte de Lótman, Egórov escreveu sua biografia), Kójinov já havia iniciado a jornada que o tornaria um dos principais recuperadores do pótchvennitchestvo. No florescimento da discussão, Egórov produziu um artigo que inscreveu a cultura e a perspectiva dos eslavófilos e dos ocidentalistas em um sistema semiótico mais amplo, de forma a projetar e enfatizar uma semelhança tipológica ao invés de diferenças irreconciliáveis entre eles. ${ }^{9}$ Kójinov também buscou relaxar a oposição entre eslavófilos e ocidentalistas, mas fui muito mais longe do que Egórov. Kójinov enxergou como característica subjacente do eslavofilismo sua insistência na singularidade e originalidade da Rússia, ao invés da filiação ao tradicionalismo e aos valores aristocráticos. Ele insistia que essa doutrina não tinha "coloração política", mas era compartilhada por pensadores de todo espectro ideológico: populistas, monarquistas, socialistas, aristocratas e democratas. A mesma variedade, para Kójinov, podia ser observada entre os ocidentalistas. Isso leva à conclusão de que não havia nenhuma "linha divisória ideológica" entre eslavófilos e ocidentalistas: ambos almejavam compreender objetivamente a essência do percurso histórico e da cultura russa"; cada grupo apreendia certos aspectos da verdade, e perdia outros. ${ }^{10}$ (Essa complementaridade, sem dúvida, remete o leitor à máxima de Berdiáev (1947, p.39): “os dois lados amavam a Rússia; os eslavófilos como uma mãe, os ocidentalistas como um filho".)

O ressurgimento da ideia conservadora da singularidade da Rússia às vezes se baseou explicitamente em emblemáticos pensadores e escritores russos do século XIX, principalmente Dostoiévski. Iuri Davídov, outro intelectual que começou como especialista e conhecedor do pensamento alemão, escreveu textos esclarecedores sobre Spengler e Weber, remobilizou o famoso elogio de Dostoiévski ao espírito russo, naturalmente - e singularmente - inclinado a "toda a humanidade" (note-se a tensão entre o universal e o particular nessa afirmação). Todas as nações, Davídov escreveu em 1982, emprestando os argumentos de Dostoiévski, são orientadas em direção à universalidade; elas existem em um modo dual, sustentado entre o solo nativo e o absoluto moral de "toda a humanidade". Cada nação tem seu próprio destino e caminho em direção à universalidade. A partir dessa afirmação, Davídov (1982, p.268) infere que as diferentes nações devem realizar seu percurso em ritmos distintos e encontrar-se em diferentes estágios de sua jornada para o absoluto moral. O Ocidente, que uma vez esteve unido à Rússia pela ideia moral sublime que convoca ao autossa- 
crifício pelo bem de toda a humanidade, há muito desistiu do objetivo de atingir o absoluto, e tudo que resta são monumentos mortos de sua antiga grandeza de espírito; é assim que Davídov interpreta o desejo de Ivan Karamázov de visitar a Europa, esse "querido cemitério". O destino da Rússia, por outro lado, é completar a jornada, atingir, em prol do mundo, o absoluto moral que todas as nações são convocadas a perseguir, mas apenas algumas (uma, na visão de Davídov) podem realmente alcançar. Voltando-se para Os demônios, de Dostoiévski (2004, p.52), Davídov evoca a convicção de Chátov sobre a singularidade do povo russo: "Se um grande povo não crê que só nele está a verdade (precisamente só e exclusivamente nele), se não crê que só ele é capaz e está chamado a ressuscitar e salvar a todos com sua verdade, então deixa imediatamente de ser um grande povo e logo se transforma em material etnográfico, mas não em um grande povo". O messianismo de Davídov é alimentado pelo apelo de Dostoiévski à Rússia como a única nação sobrevivente que está envolvida na busca por um absoluto moral; ninguém mais acompanha o povo russo nessa árdua jornada, e sozinhos eles estão destinados à batalha de autossacrifício em nome de todos os outros povos. A virada original (ainda que não muito convincente) de Davídov para essa história ademais banal é a tentativa de revisar e suavizar a oposição entre Dostoiévski e Tolstói (cuja elaboração clássica foi realizada na Era de Prata, notadamente por Merejkóvski e, desde então, havia se tornado um dos topoi do conservadorismo estético, não apenas na Alemanha, onde foi adotado por Moeller van den Bruck e Spengler). Aqui, Tolstói é colocado não como antagonista, mas como receptor de um conjunto de valores compartilhados que seus heróis materializam. A ressurreição moral que estava além do alcance dos personagens "demoníacos" de Dostoiévski é alcançada pelos protagonistas de Tolstói, disparadas por ideias de trabalho, solo e solidariedade. ${ }^{11}$

A elevação da literatura russa do século XIX a um reservatório de ideias filosóficas indispensáveis, desejo expresso por Davídov (1972, p.6-7) em seu livro, foi uma característica da restauração dos discursos de excepcionalismo a partir do final dos anos 1960. Ao mesmo tempo, Geórgui Gátchev (1973, p.110-24), inspirado em Tiútchev, Daniliévski, Spengler, Lev Gumilióv e Dostoiévski (cujo "cosmos" ele discutiu em um ensaio anterior ${ }^{12}$ ), começou a explorar a entidade fugidia que ele chamou de "logos-cosmo-psíquico", uma unidade indivisível e primordial de psicologia, linguagem e visão de mundo específica que caracteriza cada nação e se manifesta nas várias formas da vida nacional.

Uma vez que as nações apresentam diferentes entidades cosmo-psíquico-lógicas, elas também têm distintas imagens do mundo e de outras nações. Essas imagens refletem a reivindicação de singularidade de que todas as nações parecem usufruir na teoria cultural de Gátchev. Ele não é um excepcionalista cabal. À primeira vista, a reinvindicação russa de singularidade é tão legítima quanto a de qualquer outra nação. O momento em que Gátchev se afasta dessa visão tolerante é quando adota e propaga uma filosofia xenófoba e, às vezes, antissemita da história russa. Ele professa uma versão negativa do excepcionalismo. 
À diferença de outras grandes nações, a Rússia sempre teve necessidade de um líder forte estrangeiro: os tártaros-mongóis, os alemães (durante o reinado de Pedro, o Grande), "o socialismo teuto-judaico" do período de Lenin, o "Djugachvíli georgiano" e depois uma série de líderes ucranianos (khokhly-malorossy, na linguagem de Gátchev), começando com Khruschióv. ${ }^{13} \mathrm{O}$ colapso da União Soviética foi julgado por Gátchev como, ao mesmo tempo, perda (do Império) e ganho (da autonomia da nacionalidade), um toma-lá-dá-cá entre Rossíia e Rus.

A oscilação entre Império e nação também marcou os escritos de Lev Gumilióv, especialmente nos últimos anos. Sua obra é importante para a nossa discussão, pois revela as complexas modificações do eurasianismo emigrado e as subsequentes (des)continuidades que embasara a compreensão de Gumilióv sobre a história russa. O filho de Nikolai Gumilióv e Anna Akhmátova (que sofreu durante anos com o traumático distanciamento de sua mãe) foi preso quatro vezes e passou anos no gulag, para, enfim, desfrutar de relativa estabilidade e liberdade de pesquisa, depois de 1956, e mesmo de um período de glória outonal, no final dos anos 1980 e começo dos anos 1990 (ainda fomentado por seus numerosos seguidores na Rússia). Mais conhecido por Etnogênese e a biosfera da Terra, defendido como segunda tese de doutorado em 1974 e publicado oficialmente apenas em 1989, ${ }^{14}$ Gumilióv devia muito a Daniliévski e, com consideráveis qualificações, também a alguns representantes do eurasianismo no entreguerras (principalmente Savítski, Vernádski e, em menor medida, Trubetskói). A linha de Daniliévski pode ser traçada ao longo de toda a história do eurasianismo (originalmente um movimento intelectual dos russos emigrados fundado em Sófia e influente em vários momentos entre os segmentos da emigração em Praga, Paris, Belgrado, países bálticos e China (1921-1938). Ele ressurgiu na Rússia pós-soviética em uma versão que carregava apenas uma semelhança limitada com a plataforma eurasiana anterior à Segunda Guerra Mundial).

\section{Epílogo}

A filosofia e o pensamento social na União Soviética foram, nas apropriadas palavras de Evert van der Zweerde, ${ }^{15}$ o produto de uma cultura histórica específica. No que diz respeito ao contexto social no qual essa filosofia operava, o regime soviético era justamente criticado como opressor. ${ }^{16}$ Uma perspectiva de longo prazo, contudo, pode sugerir uma continuidade bastante desanimadora. Ao examinar os processos de educação filosófica, Frances Nethercott estabeleceu paralelos consistentes entre a União Soviética e a Rússia tsarista. Assim como na União Soviética, o ensino e estudo da filosofia na Rússia do século XIX estava longe de ser livre de restrições. Foi severamente limitado nas universidades depois do levante dezembrista de 1825 , banido depois de 1848, retomado em 1863 e novamente banido em 1884, para mencionar apenas alguns dos muitos marcos perturbadores desse percurso. ${ }^{17}$ Tais "banhos quentes e frios" sucessivos, como coloca Nethercott, levaram a uma formação espontânea de círculos informais, um "subsolo" filosófico, em que a qualidade da instrução, ou mesmo da 
produção, não era necessariamente elevada. Dessa forma, o verdadeiro legado da cultura intelectual soviética poderia, portanto, ter sido o cultivo de uma sociedade civil emergente, a reforma popular da esfera pública sustentada por pelo menos duas gerações de dissidentes desde os anos 1960, que prepararia a Rússia para uma era não patriarcal de liberdade sem guia ou garantias. Como se pode confirmar pelos anos pós-soviéticos, as coisas se mostraram muito mais complicadas. Os discursos de excepcionalismo continuam a prosperar, competindo com as vozes, comparativamente fracas, do pluralismo democrático e liberal. Ao mesmo tempo, a atração intelectual do marxismo parece ter desaparecido, a não ser para uma pequena elite.

Contudo, se examinarmos os destroços do marxismo soviético - ou seus híbridos ilícitos que estavam minando a ortodoxia marxista por dentro - seria possível encontrar verdadeiros exemplos de empreendimentos intelectuais elevados que merecem sobreviver às mudanças tectônicas da história. Gostaria de concluir mencionando brevemente um caso fascinante e excepcional de continuidade, surgido precocemente no fim dos anos 1960, entre o marxismo soviético e o pensamento soviético inicial, um caso em que o que estava destinado a ser uma genuína peça marxista de ciência histórica acabou por transcender as fronteiras entre as disciplinas e quebrou a redoma do marxismo. Boris Pórchnev, indiscutivelmente o filósofo russo da história mais sofisticado do século XX, escreveu em meados dos anos 1960 a obra Sobre o início da história da humanidade, publicada postumamente em versão reduzida. ${ }^{18}$ Com esse livro, Pórchnev, que já gozava de reconhecimento internacional como historiador da França do século XVII, se aventurou numa área que ele designava como "paleopsicologia". Projetado como a segunda parte de uma obra em três volumes intitulada Uma critica da história da humanidade (Pórchnev, 2007, p.11), ${ }^{19}$ o livro devia abordar a questão da antropogênese, de modo a estabelecer (na verdade, abreviar radicalmente) a verdadeira duração da história da humanidade e a usar essa premissa para abordar a lei de aceleração que Pórchnev havia identificado na história, e suas implicações para o marxismo e para a sociedade comunista. Ao conjugar história e paleopsicologia, Pórchnev pretendeu finalmente historicizar a própria fundação da história: a espécie humana, até então, tomada como uma substância imutável. Ele encontrou apoio na obra de Marr (cuja semântica paleontológica sustentou o estudo da linguagem, do folclore e dos artefatos pré-históricos nos anos 1930, e que Pórchnev enalteceu abertamente quando as ideias de Marr haviam caído há muito tempo no esquecimento pelo establishment) e na teoria de Pávlov sobre o "sistema de segundo sinal", na "dominante" de Úkhtomski e no modelo de Vygótski de desenvolvimento da consciência na criança. Em um artigo que resume suas teses centrais, Pórchnev argumenta que a história humana pode ser explicada pelo trabalho da sugestão (sugguéstiia), a atividade psíquica nuclear (mas também para Pórchnev, o ato nuclear de opressão) que distinguiu o homem no reino animal. A história humana é interpretada por Pórchnev como uma luta épica entre uma série consecutiva 
de sugestões socialmente produzidas (que envolvem atos correspondentes de contrassugestão) (cf. Pórchnev, 1971, p.7-35). Não a luta de classes como tal, mas sim a sequência de dois toques, de sugestão e contrassugestão, é o motor de funcionamento constante da história. A alienação de um homem em relação a outro sob o capitalismo é apenas uma variedade de uma contrassugestão de larga escala, que tem entre suas manifestações, segundo Pórchnev, a introdução de relações mais avançadas baseadas no dinheiro (ou seja, indiretas). O riso, para voltar a Bakhtin, também tem uma natureza dupla para Póchnev: ele age como um mecanismo de sugestão (construção de grupos e nações; Pórchnev também ressalta o papel das festas, das celebrações coletivas, do excesso de bebida e comida), mas também como mecanismo de contrassugestão (a paródia ou a excomunhão dos outros, a criação de desconfiança ou de um sentimento de superioridade contra a uma comunidade rival ou em relação a uma mensagem sagrada), revelando alegria e opressão na mesma medida (ibidem, p.25). A luta incessante que o homem tem travado desde o começo da história (para Pórchnev, não existe uma "era dourada" de liberdade e igualdade primordial) deve terminar apenas com o comunismo, quando a ciência e a verdade do marxismo finalmente removerão a necessidade do homem de esquadrinhar o ambiente e a informação constantemente recebida através do "filtro da desconfiança".

Se isso soa muito otimista ou ingênuo, não é diferente de nenhuma outra profecia sobre o fim da história - o que pode servir de lembrete de que a história do pensamento no período soviético também deve permanecer aberta, como fonte de inspiração e advertência.

\section{Notas}

I Para a lista, cf. Somerville (1946, p.235).

2 Para tradução em inglês, cf. Bogdánov, Tektology (1996).

3 Ver a principal obra de Valentin Ásmus, Ótcherki istórii dialéktiki v nóvoi filossófii (1930). Em sua resenha desse livro, Beridáev se mostra tão impressionado com o conhecimento e cultural filosófica de Ásmus que pensou que sua adesão ao marxismo era apenas "acidental" (citado em Sokolov, 2009, v.2, p.97-102).

4 Cf. Ivan Il (1918). A aprovação de Lenin sobre o livro é registrada por Tschiževsky em Hegel bei den Slaven (1934, p.374, n.15).

5 Esse detalhe e as demais informações factuais sobre as publicações de pensadores não marxistas na União Soviética até 1991 foram retiradas de Stanislav Dzhimbinov (1994, p.11-22 - o artigo foi primeiramente publicado em russo em 1992).

$6 \mathrm{O}$ artigo de Lóssev se mantém apenas como um resumo expandido organizado em tópicos: 'Filológuiia i estétika Konstantina Aksákova' (1928) in Lóssev (1997, p.94$100)$.

7 Sobre a discussão, com contribuições de quinze oradores, ver Gánitchev (1941, p.97100). Ver também o artigo de Dmítriev "Západniki i slavianofily" (1941, p.39-49).

8 O capítulo 7 é intilulado "Spór o Lérmontove" e discute Lérmontov e os eslavófilos. 
9 Cf. Egórov, "Slavianofílstvo, západnichestvo i kulturológiia” in Trudy po znákovym sistiémam, v.VI, p.265-75 (Utchiénye zapiski Tártuskogo gossudárstvennogo universitiéta, 308 (1973): Sbórnik naútchnykh statéi v chest' Mikhaila Mikháilovicha Bakhtina (k 75-letiiu so dniá rojdiéniia), ed. Iu. Lótman).

10 Todas as citações de Vadim Kójinov são de "O glávnom v nasliédii slavianofílov" in V. A. Fatéiev (2009, p.877-99, aqui p. 881-2 (publicado pela primeira vez em Vopróssy literatury, 10 (1969), 113-31).

11 Davídov (1972, p.273). Davídov fala explicitamente sobre a necessidade de revisar a oposição entre Dostoiévski e Tolstói (mencionando Merejkóvski) na introdução ao livro, p.8.

$12 \mathrm{O}$ volume é em comemoração ao $75^{\circ}$ aniversário de Bakhtin; Gátchev, juntamente com Kójinov e Serguei Botcharov, foi responsável pela redescoberta de Bakhtin na União Soviética na primeira metade dos anos 1960.

13 Gátchev, "Kosmosofiia Rossii” [1990] in Gátchev, Kosmo-psikho-logos, p.459-64, aqui p.462. A avaliação de Gátchev sobre a cultura e pensamento judaico é com frequência perpassada por acessos de condescendência de desprezo (ver o ensaio "Evreiskii obraz mira”, ibidem, p.484-503). Em 1991, Gátchev havia preparado um manuscrito de setecentas páginas sobre a mentalidade judaica (cf. Gátchev (2008, p.527).

14 Há uma versão condensada em inglês sob o título Ethnogenesis and the Biosphere (Moscou: Progress, 1990).

15 Cf. Zweerde, Soviet Historiography of Philosophy, esp. p.26-31; ver também Nikolai Plotnikov, "Soviétskaia filossófiia: institut i funktsiia” in Mikhail Ryklin et al. (2002, p.287-302).

16 Cf. Iakhot (1981), onde o leitor pode encontrar mais informações factuais sobre a canonização do marxismo-leninismo, inclusive uma discussão sobre a importante resolução do partido de 1931 (sobre o jornal Sob a bandeira do marxismo) e o infame Curso breve (1938).

17 Ver descrição de Nethercott no ensaio, "Philosophieren unter Stalin und unter Nikolaj I" in Klaus-Dieter Eichler and Ulrich Johannes Schneider (eds.), Russische Philosophie im 20. Jahrhundert (1996, p.23-34, aqui p.30).

18 Pórchnev (1974); esta versão condensada foi seguida por uma mais completa, mas textualmente não tão confiável (São Petersburgo, 2006). As referências citadas são da versão mais recente, sem cortes e textualmente mais rigorosa do livro, editada por Oleg Vite (São Petersburgo: Aleteia, 2007).

19 Em texto inédito, Pórchnev atribui o ano de 1924 para a ideia da trilogia (ver Oleg Vite, "'Ia - stchástlivi tcheloviék". Kniga "O natchále tcheloviétcheskoi istóri” i ee miésto v tvôrcheskoi biográfii B. F. Pórchneva' in Pórchnev, O natchále, p.576-706, aqui p.577).

\section{Referências}

ÁSMUS, V. Ótcherki istórii dialéktiki v nóvoi filossófii. Moscow; Leningrado: Gossudárstvennoe izdátelstvo, 1930.

BAKHTIN, M. Sobránie sotchiniénii. Moskvá: Rússkie slovari, 2000. v.II.

BERDYAEV, N. The Russian Idea. London: Geoffrey Bles; The Centenary Press, 1947. 
BOGDÁNOV, A. Tektology [Book 1]. Ed. Peter Dudley. Hull: Centre for Systems Studies, 1996.

CHARÁPOV, I. P. Litsei v Sokolnikakh. Ótcherk istórii IFLI - Moskóvskogo institúta istórii, filossófii i literatury ímeni N. G. Tchernychévskogo (1931-194l gg.). Moskvá: AIRO-XX, 1995.

CHPET, G. Ótcherk razvitiia rússkoi filossófii. Piérvaia tchast. Petrogrado: Kolos, 1922.

DAVÍDOV, I. Étika liubvi i metafizika svoevóliia (probliémy nrávstvennoi filossófii. Moskvá: Molodáia gvárdiia, 1982.

DEBORIN, A. M. Lenin kak myslitel. 3.ed. exp. Moskvá: Gossudárstvennoe izdátelstvo, 1929.

DMÍTRIEV, S. S. Slavianofíly i slavianofíl stvo. Istórik-marksist, v.1, p.85-97, 1941.

Západniki i slavianofíly. Molodói bol’shevík, v.11, p.39-49, 1941.

DOSTOIÉVsKi, F. M. Os demônios. Trad. Paulo Bezerra. São Paulo: Editora 34, 2004.

DRUJÍNIN, N. Guértsen i slavianofíly. Istórik-marksist, v.1, p.125-45; 197-200, 1939.

DZHIMBINOV, S. The Return of Russian Philosophy. In: SCANLAN, J. P. (Ed.) Russian Thought after Communism. The Recovery of a Philosophical Heritage. Armonk; London: M. E. Sharpe, 1994.

EGÓROV, B. Jiizn i tvórchestvo Iu. M. Lótmana. Moskvá: Nóvoe literatúrnoe obozriénie, 1999.

Slavianofílstvo, západnichestvo i kulturológiia. Trudy po znákovym sistiémam, v.VI, p.265-75 (Utchiénye zapíski Tártuskogo gossudárstvennogo universitiéta, 308 (1973): Sbórnik naútchnykh statéi v chest’ Mikhaila Mikháilovicha Bakbtina (k 75-letiiu so dniá rojdiéniia), ed. Iu. Lótman).

EICHLER, K.-D.; SCHNEIDER, U. J. (Ed.) Russische Philosophie im 20. Jahrhundert. Leipziger Universitätsverlag, 1996.

FEDOROV, N. Sotchiniéniia. Ed. A. Gulyga. Moskvá: Mysl', 1982.

GÁCTHEV, G. D. Kosmos Dostoevskogo. In: KONKIN, S. S. (Ed.) Probliémy poétiki i istórii literatury. Saransk: Mordovski gossudárstvenni universitiét ímeni N. P. Ogarióva, 1973.

GÁNITCHEV, I. Obsujdiénie dokláda S. S. Dmítrieva 'Slavianofíly i slavianofílstvo'. Informátsiia o diskússii. Istórik-marksist, v.1, p.97-100, 1941.

GÁTCHEV, G. D. Mentál nosti narôdov míra. Moskvá: Eksmo Algoritm, 2008.

GINZBURG, L. Tvórtcheski put Lérmontova. Leningrado: Gosudárstvennoe izdátel' stvo 'Khudôjestvennaia literatura', 1940.

IAKHOT, I. Podavliénie filossófii v SSSR (20-30 gody). New York: Chalidze Publications, 1981.

IUDIN, P. Geórgui Valentínovitch Plekhánov (K 25-liétiiu so dniá smiérti). Moscow: OGIS; Gospolitizdat, 1943.

IVAN Il. Filossófiia Gégelia kak utchênie o konkriétnosti Bóga i tcheloviéka. 2v. Moscow: G. A. Leman and S. I. Sakharov, 1918. 
KHOMIAKÓV, A. S. Stikhotvoriéniia i drámy. Ed. B. F. Egórov. Leningrado: Soviétskii pissátel', Leningrádskoe otdeliénie, 1969.

KÓJINOV, V. O glávnom v nasliédii slavianofílov. In: FATÉIEV, V. A. (Ed.) Slavianofíl stvo: Pro et Contra. 2.ed. São Petersburgo: Izdátelstvo Sankt-Peterburgskogo universitiéta, 2009.

KOZLOVA, L. A. Institut Krasnoi Professury (1921-1938). Istoricheskii ocherk. Sotsiologuicheskii jurnal, v.1, p.96-112, 1994.

LÓSSEV, A. Dialéktika mífa. Moscou: Mysl', 2001.

Ímia: izbrannye rabóty, perevódy, bessiédy, issliédovaniia, arkhionye materiály. Ed. A. A. Takho-Godi. São Petersburgo: Aleteia, 1997.

MÍTIN, M. B. Filossófskaia naúka v SSSR za 25 let. Doklád, protchítannyi na siéssii Akadiémii naúk SSSR. 18 noiabriá 1942 g. Moscow: Ogiz; Gospolitizdat, 1943.

PAZUCHIN, E. A. Studium und Entwicklung der Tradition der russischen religiösen Philosophie vom Anfang des 20. Jahrhunderts im Milieu der religiösen Leningrader Intelligenz von den 70-er Jahren bis heute. In: MÜLLER, E.; KLEHR, F. J. (Ed.) Russische religiöse Philosophie. Das wiedergewonnene Erbe: Aneignung und Distanz. Stuttgart: Akademie der Diözese Rottenburg-Stuttgart, 1992.

PLOTNIKOV, N. Soviétskaia filossófiia: institut i funktsiia. In: RYKLIN, M. et al. (Ed.) Uskol zaiuschii kontiékst: rússkaia filossófiia v postsoviétskikh uslôviiakh. Moscow: Ad Marginem, 2002.

PÓRCHNEV, B. Kontrsugguéstiia i istóriia. In: PÓRCHNEV, V. B.; ANTSÍfEROVA, L. I. (Ed.) Istóriia i psikhológiia. Moscow: Naúka, 1971.

PÓRCHNEV, B. O natchále tcheloviétcheskoi istóri: probliémy paleopsikhológi. Moscow: Mysl', 1974.

2007.

. O natchále tcheloviétcheskoi istóri. Ed. Oleg Vite. São Petersburgo: Aleteia,

SCANLAN, J. P. Marxism in the USSR. A Critical Survey of Current Soviet Thought. Ithaca; London: Cornell University Press, 1985.

SOKOLOV, V. V. 'V. F. Ásmus i dramatítcheskie momiénty ego filossófskogo tvórchestva i filossófskoi jízni. Voprosy filossófi, v.2, p.97-102, 2009.

SOMERVILLE, J. Soviet Philosophy: A Study of Theory and Practice. New York: Philosophical Library, 1946.

TSCHIŽEVSKY. Hegel bei den Slaven. Reichenberg: Gebrüder Stiepel, 1934.

WETTER, G. Dialectical Materialism. A Historical and Systematic Survey of Philosophy in the Soviet Union. Trans. Peter Heath. London: Routledge and Kegan Paul, 1960.

RESUMO - Neste ensaio estudo as continuidades que permeiam - frequentemente escondidas sob mudanças políticas dramáticas - o cenário da filosofia e do pensamento social no período soviético, da Revolução de Outubro, em 1917, à queda da URSS em 1991. PALAVRAS-CHAVE: Revolução Russa, Cultura soviética, História intelectual, Filosofia russa. 
ABSTRACT - In this essay I focus on the continuities - often hidden behind dramatic political changes - that permeate the landscape of philosophy and social thought in the Soviet period, from the October Revolution in 1917 to the demise of the USSR in 1991. KEYWORDS: Russian Revolution, Soviet culture, Intellectual history, Russian philosophy.

Galin Tihanov é "George Steiner Professor" de literatura comparada no Queen Mary College da Universidade de Londres, Inglaterra. @ - g.tihanov@qmul.ac.uk

Tradução de Priscila Marques. O original em inglês - "Russian Philosophy and Social Thought: Continuities after the October Revolution" - encontra-se à disposição do leitor no IEA-USP para eventual consulta.

Recebido em 25.9.2017 e aceito em 7.10.2017.

${ }^{\text {I }}$ Queen Mary College, Universidade de Londres, Londres, Inglaterra. 